\title{
Generative model and fixing guidelines for modular volumetric architecture
}

\section{Modelo generativo y directrices de fijación para la arquitectura volumétrica modular}

Alessandra Teribele (Main and Corresponding author)

Universidade do Vale do Rio dos Sinos (UNISINOS), Post Graduate Program in Architecture and Urbanism

Av. Unisinos, 950. Bairro Cristo Rei, CEP 93022-750, São Leopoldo/RS (Brazil)

aleteribele@unisinos.br / aleteribele@hotmail.com

\section{Benamy Turkienicz}

Universidade Federal do Rio Grande do Sul (UFRGS), Post Graduate and Research Program in Architecture (PROPAR) Rua Sarmento Leite, 320 /202, CEP 90050-170, Porto Alegre/RS (Brazil)

benamy.turkienicz@gmail.com

Manuscript Code: 1134

Date of Acceptance/Reception: 04.12.2018/14.06.2018

DOI: $10.7764 /$ RDLC.17.3.517

\begin{abstract}
Prefabricated Modular Volumetric Architecture (PMVA) needs to combine industrial-made modules with limited dimensions due to transport restrictions to attend to programs, increase space, and generate forms. Different compositions change the position and quantity of structural components and require other attributes for the connections used to fix the modules and define the building at the building site. In this study, a connective model is proposed enabling multiple compositional alternatives along with the corresponding connective guidelines. Four generic connective sets are used to simulate and define the connective guidelines, and they are then applied to three types of prisms: rectangular, trapezoidal, and triangular. The methodology, which is based on shape grammar, confirms that the use of compositional alternatives with this system depend on the geometric and constructive attributes of the connective set used to fix the modules together. The compositional variation is therefore closely linked to a compositional-connective relation and to connective sets submitted to different degrees of adjustment. The proposed model opens the way for the industry to change the connective sets used and broaden the combinatorial capacity of chassis and thereby increase the capability for mass customization.
\end{abstract}

Keywords: chassi, connective set, shape grammars, customization, industrialized production.

Resumen

La arquitectura volumétrica modular prefabricada (PMVA) necesita combinar módulos de fabricación industrial con dimensiones limitadas debido a las restricciones de transporte para atender programas, aumentar el espacio y generar formas. Diferentes composiciones cambian la posición y la cantidad de componentes estructurales y requieren otros atributos para el conjunto de conexión utilizado para fijar los módulos y definir la edificación en el sitio de construcción. En este estudio, se propone un modelo conectivo que permite múltiples alternativas compositivas junto con las pautas conectivas correspondientes. Se utilizan cuatro conjuntos conectivos genéricos para simular y definir las pautas de conexión, y luego se aplican a tres tipos de prismas: rectangular, trapezoidal y triangular. La metodología, que se basa en la gramática de formas, confirma que el uso de alternativas compositivas con este sistema depende de los atributos geométricos y constructivos del conjunto conectivo utilizado para fijar los módulos juntos. La variación de la composición, por lo tanto, está estrechamente vinculada a una relación conectivo compositiva y a los conjuntos conectivos sometidos a diferentes grados de ajuste. El modelo propuesto abre el camino para que la industria cambie los conjuntos conectivos, contribuyendo a ampliar la capacidad combinatoria de chasis y, por lo tanto, permite aumentar la personalización masiva.

Palabras clave: chasis, conjunto conectivo, gramática de forma, personalización, producción industrializada.

\section{Introduction and Problem Description}

Prefabricated architecture has advantages over traditional constructions due to the benefits of industrialization - high precision and predictability, short construction periods (Modular Building Institute, 2011) as well as increased quality control (Smith, 2011). However, its industrialized production can promote repetition and standardization, leading to the execution of similar buildings and making the customization of a building difficult.

Among the types of prefabricated constructions available, prefabricated modular volumetric architecture (PMVA) offers the greatest benefits from industrialization as well as the greatest challenges for customization. This system operates simultaneously at two locations: the factory and the build site (Garrison \& Tweedie, 2008). Three-dimensional autonomous units that form usable closed spaces called modules are produced at the factory, and the intended construction is then built at the build site by joining one or more modules (Modular Building Institute, 2011; Schoenborn, 2012). To complete the process, transportation and lifting accomplish the displacement and assembly of the modules 
at the site of deployment, and the "connective set", which comprises the pieces used to connect the modules, facilitates the module-to-module connections.

Varied compositional arrangements are needed to meet specific environmental characteristics (Rocha, 2011), the desires of the user and the aspirations of the architect designing the building to achieve a unique result (Gardiner, n.d.). The PMVA needs to combine modules with limited dimensions due to transport restrictions (Na, 2007; Schoenborn, 2012), to attend to programs, increase spaces and generate forms. In contrast, its industrialized production can promote repetition and standardization, leading to the execution of similar buildings and making the customization of a building difficult. "Conventionally understood as an assembly of boxes" (Garrison \& Tweedie, 2008, p. 4), the challenge is, therefore, to think of a method that increases the range of choices while adding efficiency via a low cost of production (Kieran \& Timberlake, 2003), and fitting in industrialized production.

Among the strategies to employ mass customization, the ability to design and produce different products in a fast and economically competitive way (Mullens, 2011; Piroozfar \& Piller, 2013), the most commonly used in PMVA is the addition of elements to the module such as balconies, shading elements, and roofs, as well as the variation in coatings, colors, openings and closings. These solutions, though, focus on the epidermis of the building and do not guarantee compositional alternatives with blocks which can have relatively inflexible sizes and shapes.

With regards to rectangular prisms, this modules' trend appears to be the original format. Rectangular prisms generate little compositional variability when they are united side-by-side or stacked without misalignment. Other variations are possible when the blocks are misaligned, thus creating protrusions and recesses as in the Verbus system (US 2007/0271857 A1, 2007), which allows for changes in the spatial relationship between modules. Changing the form of the module is another method of increasing the compositional variability. When using a trapezoidal prism and a triangular prism, buildings with curvatures can be generated as achieved by Polyghome systems (WO 2010/142032 A1, 2010) and Homb systems (US 2011/0185646 A1, 2011), respectively.

To change the form of a module and/or the spatial relationship established between blocks is related to the module structure. This structure can draw on the industrial concept of "chassi", a constant structural system that receives interchangeable components (Schoenborn, 2012). In the PMVA, the chassis becomes the module-structure formed by the components: pillars, beams and connections; and receives the other parts (chunks): sealing, floor, roof, among others; each one with its own components. In this sense, the chassis is another way of customization that is related to the module shape and the spatial relationship between blocks.

Different compositional arrangements alter the fixation requirements. The connections among blocks and the course of the structural loads are facilitated when the encounters among blocks occur vertex to vertex. When the blocks are joined at the vertex of one block to the middle of another, the vertical edges (pillars) are joined with horizontal edges (beams), thus generating unions between the vertex and the middle of the block. The quantity and the position of structural components at the junction point influence the characteristics that the connective set must have in order to meet the union of the modules.

To increase an arrangement's diversity while ensuring industrial production requirements, the fixing attributes must be anticipated, including the geometry and location of holes, pins, connectors, and plates. Different compositions may imply adjustments and adaptations of a greater or lesser degree to the connective set linking its attributes with combinatorial possibilities. The exploration of spatial relations between modules, which is the conductive thread of the compositional variability, can be performed based on the structural components, including the pillar, beam and connections, as well as the fixation attributes required in different compositions.

The generation of compositional alternatives along with the fixation guidelines involved would allow compositionalconnective integration to be "projected" in advance. Rather than the skeletal or planar components with which architects are familiar (R. M. Lawson, Ogden, Pedreschi, Grubb, \& Popo-Ola, 2005), and because architects need to become better educated about modular construction in general (Schoenborn, 2012), it is possible to explore a way to design with blocks linked to the fixation requirements. Through studies on connections, the combinatorial capacity of chassis can be enlarged, thereby increasing the capability for mass customization.

The aim of this paper is to: 1 ) demonstrate that compositional alternatives with three-dimensional volumetric modules depend on the geometric attributes of the connective set used to fix the modules together; and 2) propose a model that generates multiple compositional alternatives with volumetric modules and link these solutions the necessary guidelines to fix them. 
This study is limited to the geometric and constructive aspects of fixation between the structural components of the modules and does not cover stress, load, and structural calculations.

State of the Art

Prefabrication has been present in civil construction since the beginning of the Industrial Revolution, but it was not until architecture and industry were joined together that the prefabricated architectural culture was born (Bergdoll \& Christensen, 2008). A renewed explosion of interest in prefabrication appeared (Bergdoll \& Christensen, 2008) after production became focused on individual needs, with the aim of stimulating consumption (Fonyat, 2013).

Currently, the varying levels of prefabrication used in construction are a) processed materials; b) prefabricated components; c) panelized structures; and d) modular structures (Garrison \& Tweedie, 2008; Schoenborn, 2012), as shown in Figure 1 . The last of these are architectures that use the PMVA system, a construction process in which a building is built outside of the place where it will be implanted (Modular Building Institute, 2011; Velamati, 2012). The mains steps involve: 1) project development and approval; 2) module and component assembly; 3) module transportation and; 4) module installation on the land (Modular Building Institute, 2011; Velamati, 2012). The materials most commonly used to produce modules are timber, steel, and concrete. In both of these cases, the blocks need to encompass the 1) services within the module (electrical cables, hydraulic ducts, wiring and others); 2) enclosure components (cladding, roofing, floor) and; 3 ) structures, all of which should be developed and installed at the factory (Lawson, Ogden, \& Goodier, 2014).

Figure 1: Classification of prefabricated systems used on construction. Source: Author based in Garrison \& Tweedie (2008).

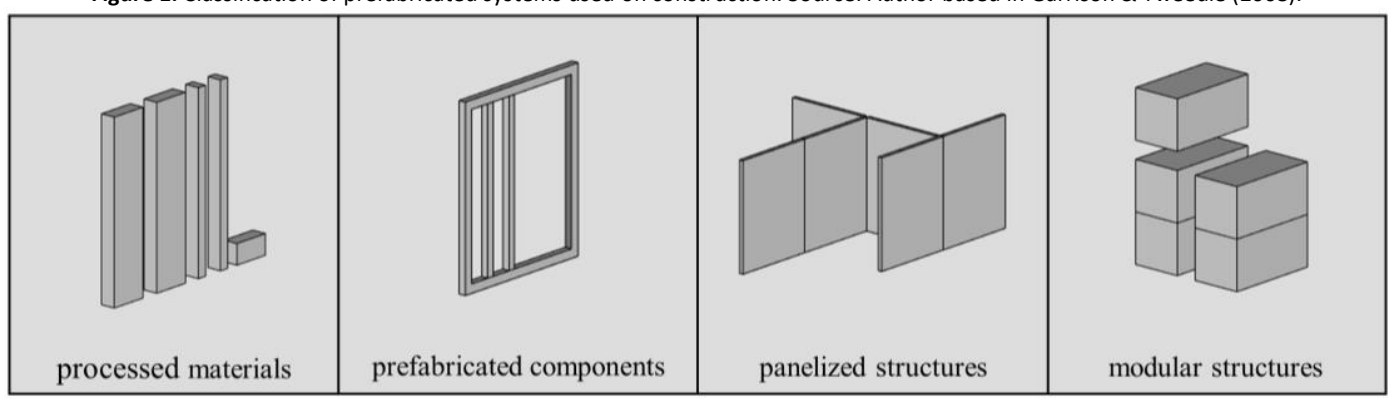

The modules arrive at the final building site almost entirely constructed, to a degree of approximately 85\% (Smith, 2010), and are then joined together to assemble the final building. The modules are attached to the foundations, which have been prepared in advance. The services inside the modules are connected to central services, and the building drainage is finalized (M. Lawson et al., 2014).

Due to the independent structures of the modules, their union can bring on wall duplication that "helps in soundproofing and structural strength, but also adds redundant materials and dimensions to the building" (Cameron \& Carlo, 2007, p. 35). This wall duplication, the marriage walls, includes a small space separating them to accommodate possible errors (Cameron \& Carlo, 2007). "Tolerances exist to accommodate the normal manufacturing and installation inaccuracies that occur in construction (...)" (Smith, 2011, p. 210). Finishes are made to guarantee building insulation after the end of assemblage (Garrison \& Tweedie, 2008).

The blocks must be connected to each other to ensure the structural efficiency of the entire edification. The joint points connect module-to-module both horizontally and vertically through connective sets. The connective sets result from pieces (plates, pins, holes, etc.) aggregated in the module, even in the fabric, and the pieces (plates, pins, screws, etc.) aggregated in the building during on-site assemblage. Connections between modules are structurally important because they influence the entire structure (Lawson et al., 2014).

The volumetric units must be joined to generate spaces and answer diverse architectonics programs while also maintaining rational industrial production. However, more standardized systems present less flexibility (Anderson \& Anderson, 2007), thereby hindering compositive variability. The term "industrial" is still associated with monotony, particularly in households, where individual desires must be accommodated (Staib, Dörrhöfer, \& Rosenthal, 2008).

The gap between architectural idealization and industrialized contemporaneous building productions (Vibaek, 2011) can be resolved by employing mass customization, which is the ability to design and produce various products in a fast and economically competitive way (Mullens, 2011; Piroozfar \& Piller, 2013). 
The construction industry uses three strategies for the mass customization of a modular volumetric house: 1) a modular product architecture, independent modules that constitute a system; 2 ) the postponement of customization, extending the process of customization to the end of the production chain and allowing changes in the industrial process to occur as late as possible; and 3) flexible production processes, to improve the ability to accommodate variations in the production process using standardization, rationalization and common methods (Mullens, 2011).

In addition to postponement, the use of plastic alternatives can be explored on the building's surface through the addition of elements to the module such as balconies, shading elements, and roofs, as well as the variation in coatings, colors, openings and closings. To enable flexible production processes, the companies develop a set of compositional solutions and produce a catalog so that customers can customize a set of predefined combinatorial alternatives from a set of premade solutions. The application of the modular product architecture in the modular volume architecture can be seen by decomposing the final product into a series of chunks, which in turn are formed by a series of components, similar to the one obtained by the automotive sector when improving its production chain (Kieran \& Timberlake, 2003). The Japanese company Sekisui Heim applies these concepts using a structural steel chassis that runs along an assembly line on which it receives the other parts of the construction: the sealing, floor, and roof, among others (Linner \& Bock, 2012).

Another step that could facilitate the attainment of mass customization in the PMVA would be the application of the technology known as CAD / CAM (CAD - computer-aided design and CAM - computer-assisted manufacturing). Since information for the construction could be generated directly from the project information (Kolarevic, 2003), this method could be applied directly in industry. Schoenborn (2012) points out that this type of technology has not yet helped the construction industry achieve this customization. CAM software, purchased along with equipment, is often unsuitable for handling custom designs. They do not have the capacity for customization that CAD software has. Small design changes lead to major modifications in the codes that command the machines, making manipulation difficult for operators. In PMVA, automation is used for repetitive processes (Schoenborn, 2012).

Most of the solutions for mass customization focus on the epidermis, the skin of the building, and do not guarantee compositional alternatives with blocks. When there is a combination between blocks, it is predefined by the industry or the whole system is adapted to fit a specific architectural design, impairing the industrial process. PMVA needs to come up with methodologies that allow a greater design freedom and extent of customization while ensuring compliance with the requirements of industrialized production.

To vary the building beyond the surface and achieve combinatorial variability, 1) the form of the module must be changed and 2) the spatial relationship established between modules must be modified. Modifying the rectangular prism which can limit the design options (Cameron \& Carlo, 2007; Na, 2007) allows for an increase in the variability of the set while allowing for the generation of buildings with curvatures as achieved by Polyghome systems (WO 2010/142032 A1, 2010) and Homb system (US 2011/0185646 A1, 2011) when using a trapezoidal prism and a triangular prism, respectively. Other variations are possible when the blocks are misaligned, which generates protrusions and recesses as in the Verbus system (US 2007/0271857 A1, 2007), which allows the spatial relationship to be changed between rectangular blocks through a connection positioned on the side of a module that joins with connections positioned in the vertex of other modules.

Changing the spatial relationship between modules can transform the final shape of the building and increase combinatorial variations, although different compositional arrangements alter geometrical and constructional requirements as well as fixation requirements. Due to its characteristics, the connective set may or may not fit the modules in the proposed arrangement. The geometry of the module, the characteristics of its structural components and the connective sets are usually characteristic of each volumetric system proposed by modular constructors (Gassel \& Roders, 2006) and the characteristics of each system influence the combinatorial diversity, as shown in Figure 2.

Studies that link compositional arrangements to fixation attributes are still not enough explored in the literature. Researchers are focused on 1) demonstrating the benefits and limitations of this type of architecture (Azhar, Lukkad, \& Ahmad, 2012; Cameron \& Carlo, 2007; Modular Building Institute, 2011; Schoenborn, 2012); 2) improving manufacturing processes by investigating the application of concepts from other industrial sectors in the construction industry, such as lean production (Alshayeb, 2011; Mullens, 2011; Mullens \& Kelley, 2004; Nahmens \& Ikuma, 2012); manufacturing automation (Diez, Pádron, Abderrahim, \& Balaguer, 2003; Furuse \& Katano, 2006), and design relationships for manufacturing (Diez, Padrón, Abderrahim, \& Balaguer, 2007; Huang \& Krawczyk, 2007; Moghadam, Alwisy, \& Al-Hussein, 2012; Nasereddin, Mullens, \& Cope, 2007) and; 3) describing the characteristics of modular systems, such as dimensional and structural aspects, types of coatings, solutions of connections, among others (Anderson \& Anderson, 2007; Lawson et al., 2014; Lawson, 2007; Lawson, Ogden, Pedreschi, Grubb, \& Popo-Ola, 2005). 
Figure 2. Examples of Modular Systems. Source: Author based in: a) (US 2011/0185646 A1, 2011); b) (R. M. Lawson, 2007) ; c) (US 2007/0271857 A1, 2007) ; d) (WO 2010/142032 A1, 2010); and e) (Anderson \& Anderson (2007).

UNION
CONNECTION STACKING CONNECTION

Therefore, this study investigates connective set attributes associated with combinatorial possibilities using the method known as shape grammar. Shape grammar with tri-dimensional shapes was first tried in 1980 (T. Knight, 2000), when Stiny used the Froebel's building gifts as a vocabulary for the generation of new forms (George Stiny, 1980). Piazzalunga and Fitzhorn (1998) simulated three-dimensional objects on the computer by implementing this grammar. Following this study (Wang, 1998; Wang \& Duarte, 2002), they automated formal generation with Froebel blocks. Koning and Eizenberg (1981) also applied the shape grammar to analyze three-dimensional blocks in extracting the grammar of Prairie Houses. They were divided into two stages: rules of basic composition and ornamental rules (T. W. Knight, 1994). Other examples of works that use more than one grammar simultaneously can be found in studies as Li (2001), Duarte (2007) and (Gonçalves, 2015). Sass (2005) employs the shape grammar to generate house designs from 3/4" plywood sheets and Mayer (2012) uses the shape grammar to demonstrate how to apply this method to social housing architectural designs.

\section{Methodology}

Based on the shape grammar method, the generative process with the PMVA links the principles of two grammars: compositive grammar and connective grammar. The former establishes the rules for combining the modules, which are used in shape grammar, and the latter describes the fixing guidelines necessary to join the blocks with the generated composition. This process is based on description grammar and is used to describe design features not covered by shape grammar (Duarte, 2007).

Through the use of a grammar of forms, it is possible to establish parallels between different grammars, relating constraints that describe relevant aspects of design according to pre-established criteria of interest (Duarte, 2007; G Stiny, 1981). It allows new design sets to be explored, and design alternatives can be achieved (Prats, 2007). They deepen the theoretical and/or practical knowledge of the problems addressed in each project (Santos, 2009).

In the proposed generative model that defines the method of combining compositional patterns, the two principles of grammar go side-by-side and act simultaneously, and they may be understood as parallel grammars (T. Knight, 2003). The aim is not to generate a grammar but to demonstrate a method of achieving it from the choice of connective attributes. This work demonstrates a method of generating several compositions simultaneously and shows the connectives guidelines to join the modules.

The methodology was divided into three parts: 1) principles of compositive grammar, which establishes compositional patterns based on the characteristics of the faces of the modules that are joined; 2) principles of connective grammar that describe the fixation guidelines needed to realize each compositional pattern with a focus on the connections 
between modules, and 3) a generative compositional-connective model that establishes the ways in which compositional patterns can be combined while guaranteeing its adherence to fixation guidelines in different degrees of adjustment. These phases are described next and are illustrated in image 3.

The fixation guidelines are defined by the simulation of four generic connective sets $(a, b, c$ and $d)$ based on solutions presented by existing volumetric modular systems and shown in Figure 4 . The components of the connective sets that are welded to the modules were adapted to the different angulations of the shapes from each modular type. The pieces placed during the assembles of the modules in the land remain in the initial format and follow the form of the original system as follows: $a$ and $d$ are rectangular prism; $b$ is triangular, and $c$ is a trapezoidal prism. The guidelines identify the following: a hole must be drilled in the components for bolt fixation; the pin/hole/plate position must be determined; the geometry and angle of fastening parts must be determined; access for fixation of the parts and the influence of the shape of the section of the beam and/or pillar to receive connections must be identified. The modules and connective sets established for this study are limited to the components of the connective sets and to the shape of the posts and beams of each of them.

Figure 3. Illustrative diagram of the methodology steps. Source: Author.
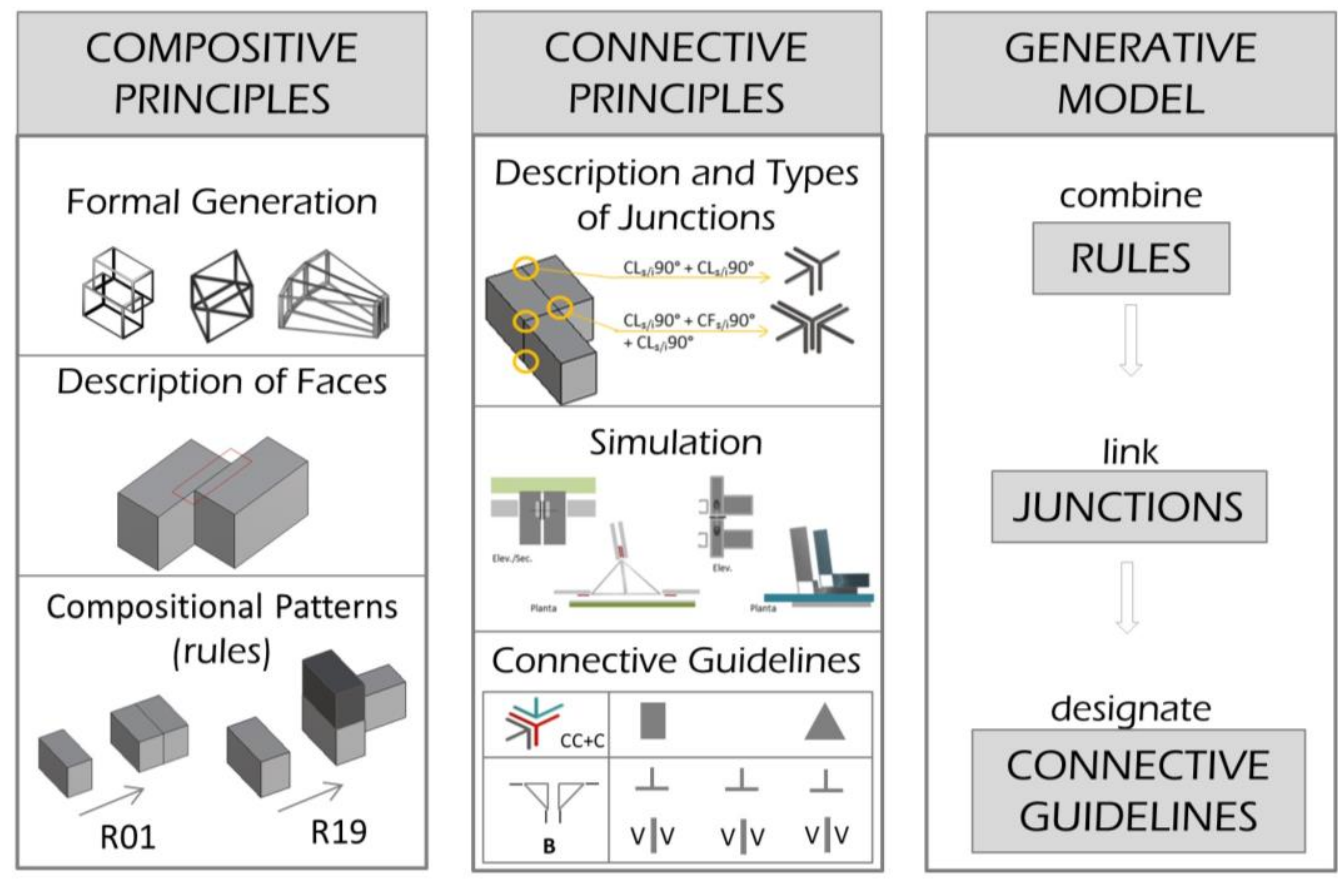

Figure 4. Types of modules and connective sets used in the methodology. Source: Author.

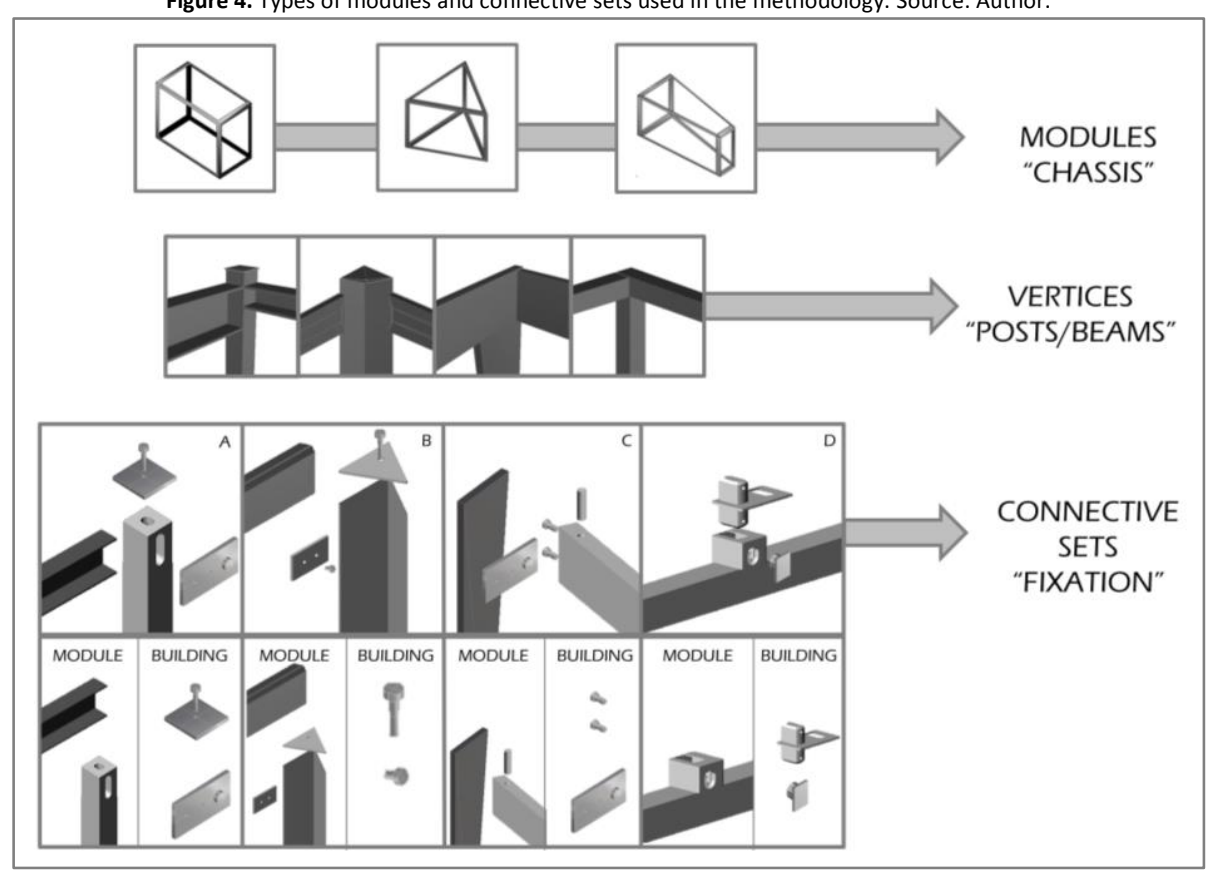


a) Connective Set A - Union made with flat metal plates (vertical) and screws placed externally on posts, which were previously bored on the front face. Stackings made with screws and flat metal plates (horizontal) between ends of the posts, with tips closed by sheet metal welded to the pillars. Holes in the external face of the pillar allow access to the fixing of the screws made by external access. The height of the pillar is greater than the upper face of the beam. The beams have a section " $C$ " with external faces aligned to the tubular pillar with a square section.

b) Connective Set B - Union made with flat (vertical) metal plates welded to the module pillar that receives two beams, one on each side, fixed by screws placed on the inner side. Stackings made by sheet metal (horizontal) welded to the tip of the pillar and fastened with a bolt accessed from the inner side of the module, which attaches the structural components of the module together with the fixings between them. The height of the pillar is greater than the upper face of the beam. The beams have rectangular sections and the pillars are in folded sheets accompanying the opening of the vertex of the modules.

c) Connective Set C - Union made of sheet metal (vertical) internal to the pillars and fastened with screws. Stackings made via pins placed in the corners of the module, the bottom side, and holes defined in the lower corners of the overlapping modules. Stacking locking (The fixing of the pins/holes in the case of stacked modules was called locking in this work) made by the external side of the building, front faces, with holes and screws covering structural components of the two modules. Pillar with rectangular sections end in the beam, also with rectangular sections.

d) Connective Set D - Joint and stacking made simultaneously with connector elements welded to the module beam. The beam has a hole in the front face for locking with vertical plates and screwed pins, and a hole in the upper face is included to receive pins and bored horizontal plates. Plates of 01 units, 02 units and 04 units were considered, where the major side joins the larger side. In the triangular prism, the connector element has a hole in both sides. The connector element is in the corner of the module and in the middle of the beam according to the displacement between blocks. Pillar and upper face of the beam, both tubular of square sections, terminate at the same height, and the accesses for fixation are external.

The connective sets were inserted into the types of junctions found in order to provide geometric and constructional requirements for fastening guidelines. These junctions are derived from three models of form, each based on one type of prism: rectangular, triangular, and trapezoidal. The principles of the two grammars and the proposed generative model are described below.

Application of the Methodology

\section{Principles of Compositive and Connective Grammar}

Two steps were used to establish the composition patterns with up to four modules. In the first step, combinations were generated with 02 modules using congruence transformations in the plane (Pottmann, Asperl, Hofer, Kilian, \& Bentley, 2007); in the second step, combinations were generated with 04 modules through a matrix, which represents a mapping arranged within an abstract mathematical structure (March \& Steadman, 1974) formed by rows and columns.

The combinatorial models were developed using the Grasshopper parametric software that is a plugin that works with the Rhinoceros program from Robert McNeel \& Associates. The models were divided into two phases for each of the three prisms, that is, rectangular, trapezoidal, and triangular, resulting in 3 forms of generation models. The established rules considered that displacements of $1 / 2$ go to union compositions and $1 / 4$ go to stacking compositions. The shapes that change the structural function of the components have been eliminated as well as those that generate a vertical mismatch of all the faces involved in the stacking.

The compositive patterns were defined from the composite-generated analysis of the face characteristics of the joining modules. Each pattern represents a compositive rule, indicated by the letter " $R$ " and a number, as demonstrated in Figure 2.

These faces allow us to describe the types of junctions present in each combinatorial arrangement from which the fixation guidelines can be described. The connective grammar links the fixation guidelines with the proposed compositions from the junction type. 
For each compositive pattern, the junction type has been identified between modules. The junction may be of the following types: a) union - modules that are side-by-side or b) stacking - modules that are overlapping. The encounter may be of the following types: a) corner - defined by the vertex of the prism where there is a junction of two beams and a pillar and/or the b) middle of the beam - defined by the junction with a beam in a position other than the corner. In addition to these typologies, the face of the component that joins with another module is either front, lateral, inferior and/or superior, and the angle between the pieces and the number of modules at the joint describe the other characteristics of the joints using letters.

Each junction type has a generic image drawn at a $90^{\circ}$ angle between the components following the description that indicates other specificities as shown in Figure 5. When the junction occurs only in one type of prism, it is drawn with the angulation that it possesses.

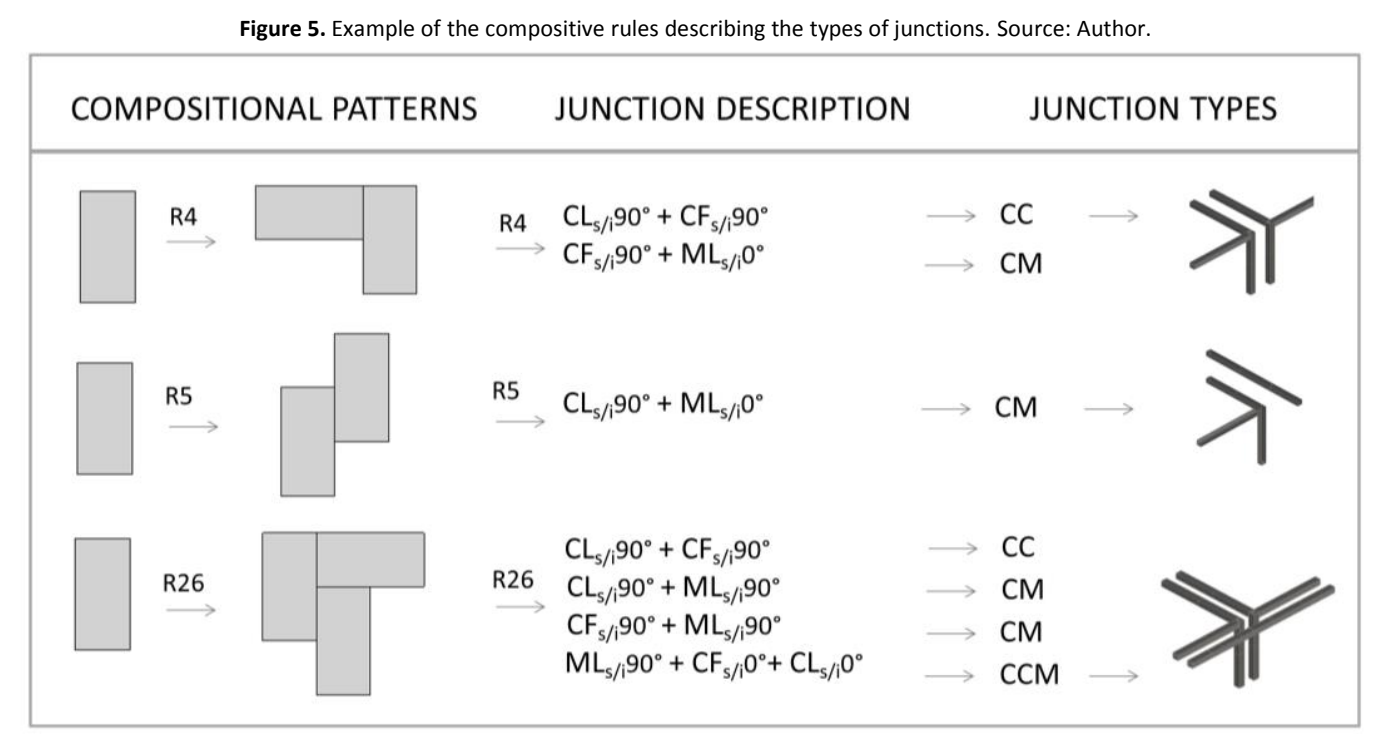

After the encounter types were identified, the connective sets were inserted into these junctions to simulate the fixation. This process was performed through two-dimensional schematic drawings considering the connective attributes based on existing systems. Each of the 4 connective sets was simulated individually for all junctions identified for the 3 prism types as shown in Figure 6.

This simulation shows that the connective sets are able to meet the junctions, and the unfit ones need a) a hole in the components for screw fixation; b) a pin/hole/plate position; c) geometric alignment for the fastening of pieces and; d) to consider the influence of the shape of the section of the beam and/or pillar to receive connections.

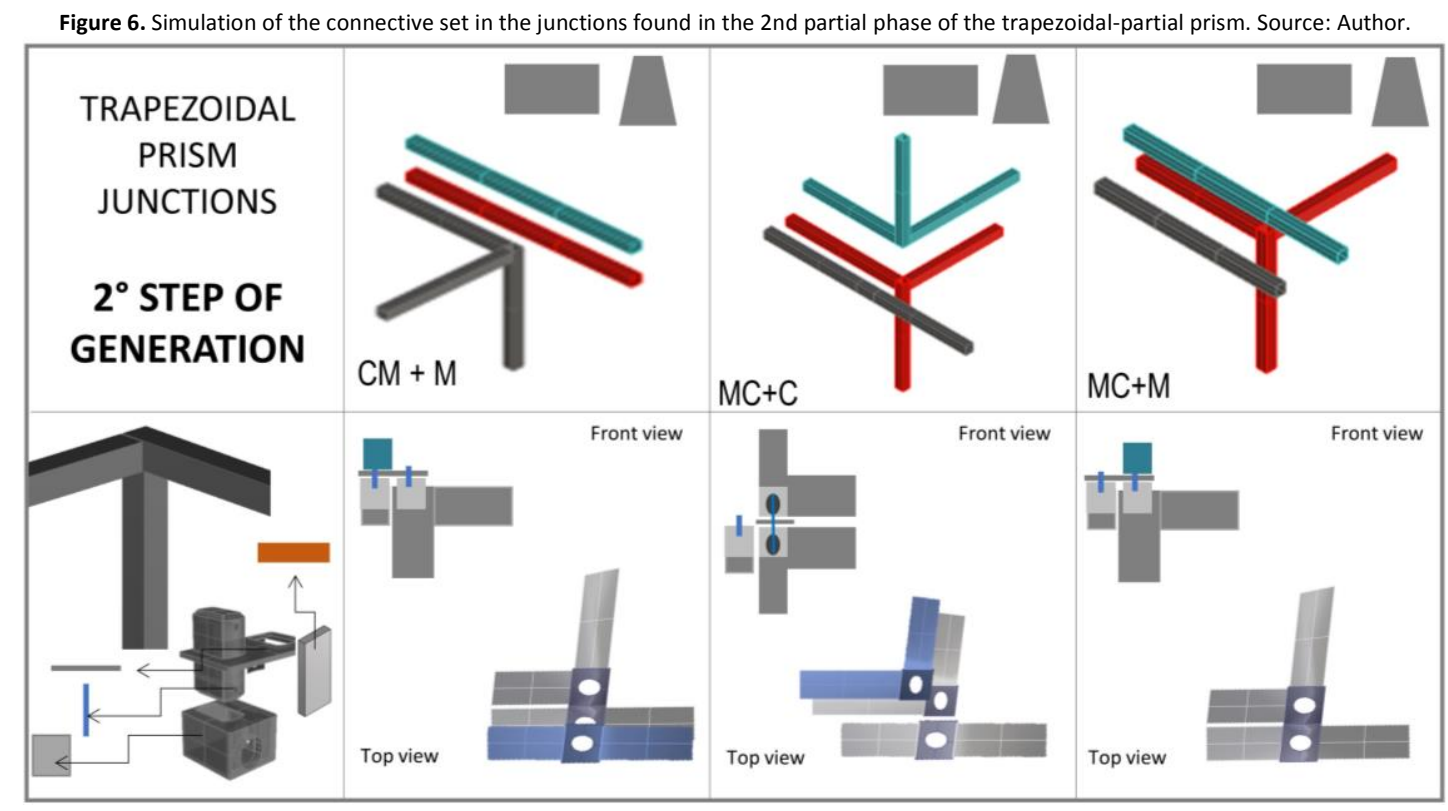


From this information, we suggest attributes that indicate the fixation guidelines. Whether the junction points can be accessed, whether the other modules prevent this access, and the constructive items that should be provided to perform the connection are included in the guidelines. These elements receive symbols that should be attached at compositive rules.

\section{Generative Compositional-Connective Model}

After the compositional patterns and fixation guidelines were defined, a model was proposed that unites the compositive and connective principles of grammars to ensure that the fixation needs for each projected arrangement are anticipated. Two methods of combining the patterns were established: a) adding patterns and; b) adding and partially replacing patterns.

For the adding patterns, junctions do not have to be added or replaced, although the method of combining the patterns must be considered, including the rule that defines this union. One must choose the rule that will meet the combination of patterns and observe how the faces will join. We added 3 rules, with 2 of the rules pertaining to each pattern and the $3^{\text {rd }}$ created by combining the previous two. Figure 4 demonstrates the addition of two patterns by two different rules.

For the adding and partially replacing patterns, 2 compositions are joined, with one module substituted for another equal module. In this case, we add only the 2 rules, 1 for each composition as shown in Figure 7. For a combination with stacked faces, junctions must be removed from the stacked face, which will join to another face after the combination because a change in the type of encounter between modules occurs.

Figure 7. Example of combining patterns. Source: Author.

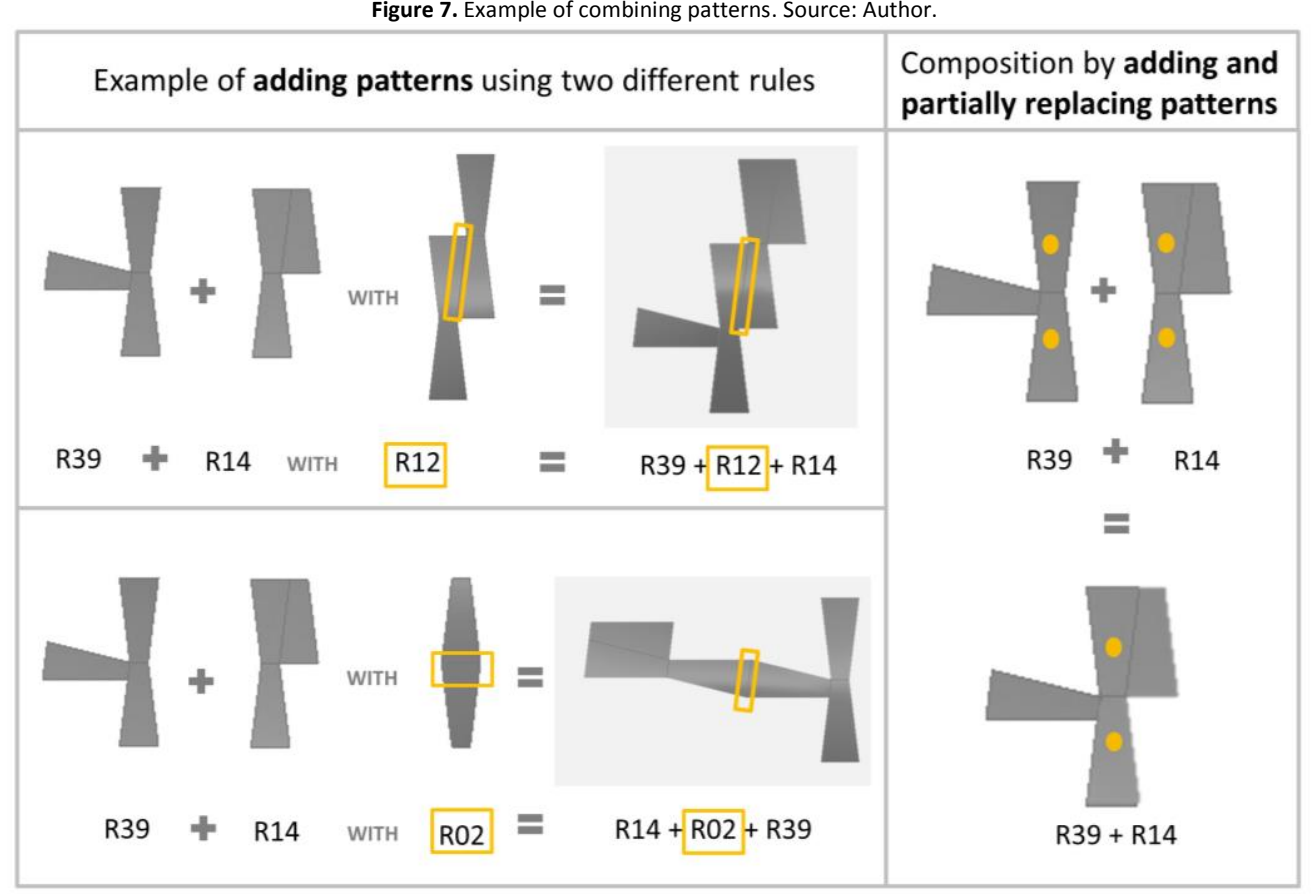

To verify the proposed generative model, certain derivations of the rules were performed: 1) compositions were made in Rhinoceros; and 2) compositions were made with blocks of wood. In both cases, the rules were selected randomly from the standards defined in Grasshopper and applied to the 3 prism types, thus providing compositional alternatives linked to the fixation guidelines. In the compositions made with the wooden blocks, the experiments were performed with the aid of a rule list to avoid unmapped combinations; therefore, the connective guidelines were not provided. The model is limited to the pre-established rules to ensure the relationship with the fixing guidelines. The creation of new rules by the different junctions of faces implies the types of generated joints. Figure 8 shows the compositive results for a rectangular prism. 
Figure 8. Composition example performed with randomly selected rules and fixing guidelines for the proposed composition with rectangular prisms. Source: Author.

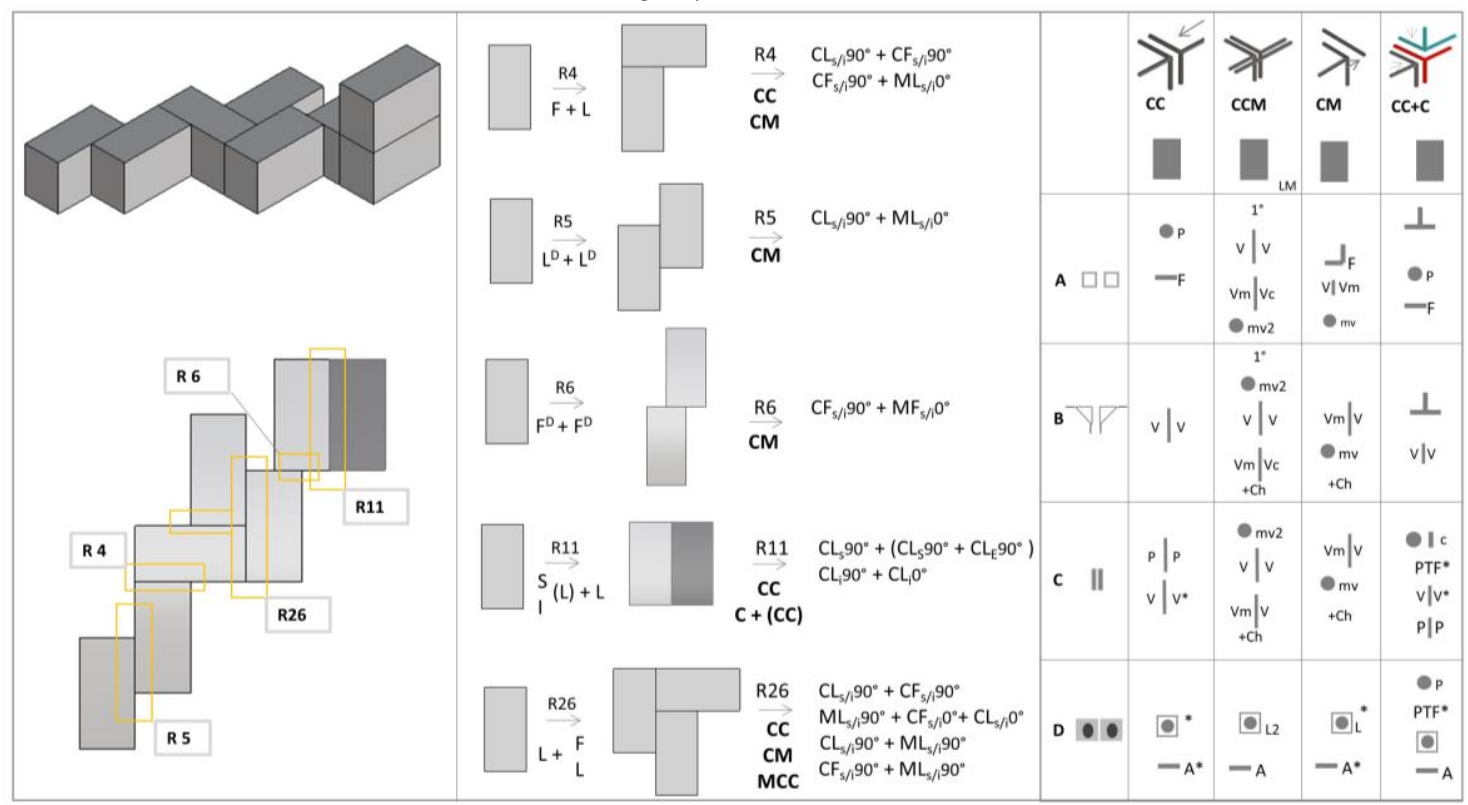

Results and discussion

Aiming to generate a combinatorial model that generates compositional alternatives with three-dimensional modules and link the compositions generated with the necessary connective guidelines to fix the modules, we worked with two grammars: the compositive and the connective. In the compositive grammar, compositional patterns were established from which the descriptions and the types of junctions defined in the connective grammar were extracted. The simulation of 4 generic connective sets in the junction types allowed the connective guidelines to be defined for each proposed standard.

The simulations were analyzed to classify the degrees of adjustment, which are modifications that the connective sets will need to undergo to meet the types of junctions generated. This analysis was divided into situations in which the connective set satisfies the unchanged join, which are represented by the symbol OK; situations that need small adjustments and maintain the method of fixation proposed by the system partially attending the connections, which are represented by the letter $P$; situations that need to be adapted by modifying and/or extending the system, which are represented by the letter $A$; and situations that need to be remodeled by revising the system to meet certain junction types, which are represented by the letter $\mathrm{R}$. These modifications are described below:

• "OK":

- flat plates are suitable for angular variations of types of prisms when joining the modules through pillars and/or beams;

- pillar whose hole allows access to the bolt and/or holes appropriate to the shape and the positioning of the pin.

- Partial - "P":

- flat plates for securing modules with front and/or top access need to be altered by adjusting the angle and shape generated between the modules;

- fix beam with beam instead of pillar with pillar, maintaining the proposal of fixation between components by internal access to the modules;

- locking the stacking by the side rather than the front;

- hole/pin in the middle beam instead of the corner;

- need to insert more holes in the structural components and/or in the connector element and/or adjust hole shape.

- Adapted - "A":

- insert plate and/or connector element in a location not provided by the system, extending the connective set;

- "L" plate (angle bracket) for fixing the components differently from the one foreseen since access to the parts is impaired;

- connect beams to each other via an internal panel by internal access to the module, thus changing the system that provides external access for fixing; 
- adapt the locking situation of the stacked modules, such as a fixing bracket fixing upper and lower modules, since the access provided by the system is prevented by the generated composition.

- Remodel - "R":

- need to study the solution to overcome the span formed between beams of different modules when stacked.

The compositional patterns generated were analyzed by the degree of modification. The obtained results demonstrated that few patterns are fully satisfied by the connective sets, and compositions with vertices of aligned modules are primarily observed, as is shown in image 9. Most of the arrangements presented depend on adjustments in the connective sets so that they can satisfy the encounters generated between the three-dimensional modules. That is, the same fixation requirements occur in the chosen composition but not all connective sets are able to meet these requirements, thus confirming the first aim that compositional alternatives with three-dimensional volumetric modules depend on the geometric and constructive attributes of the connective set used to fix the units together.

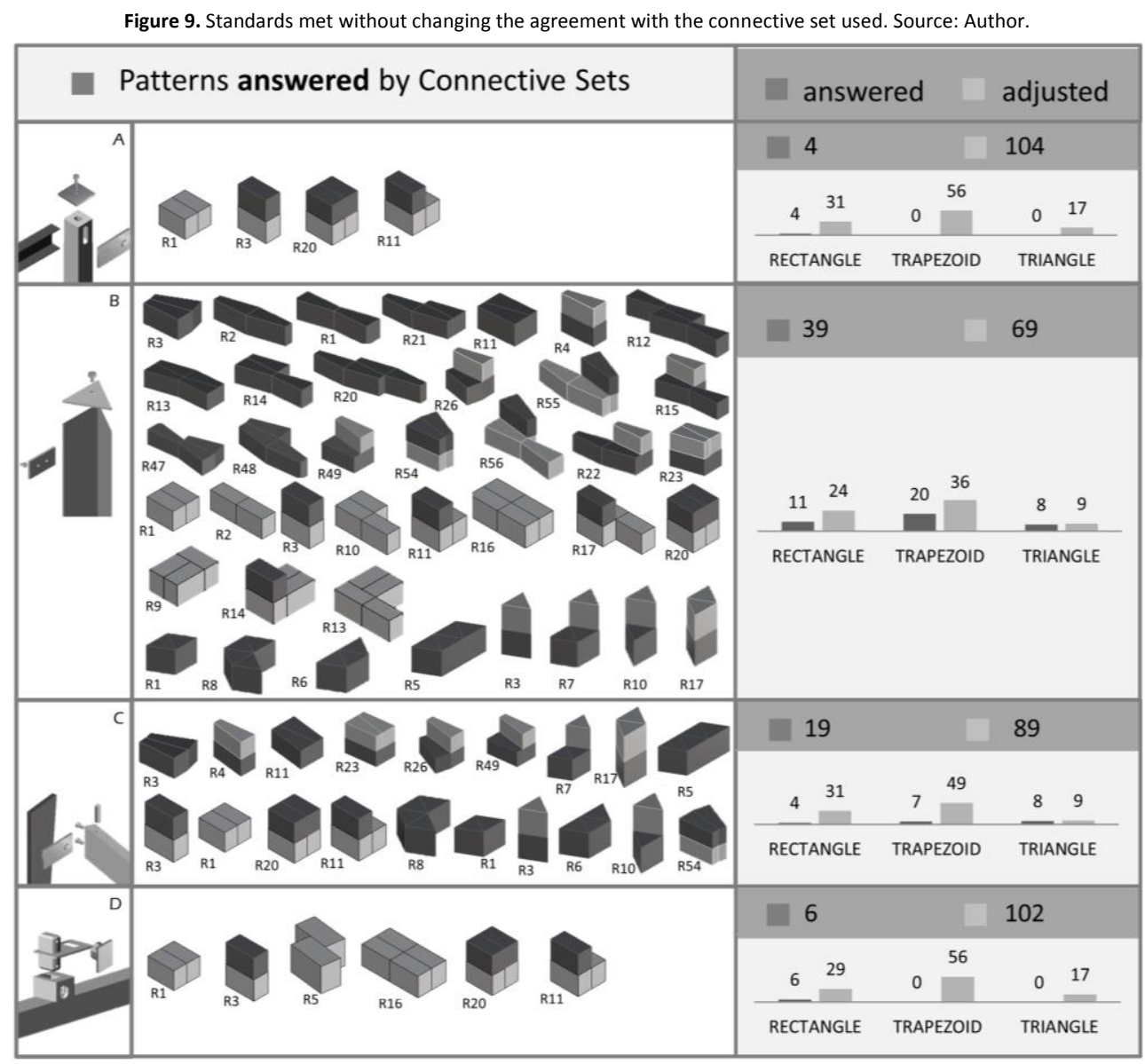

These compositional patterns serve as the basis for creating a generative model that links the fixation guidelines for each proposed composition and keeps the connection-composition relationship, achieving the second objective of this article. To combine modules while ensuring proper fixation, we should a) choose rules where connective sets fully meets the junctions formed; b) promote the modifications suggested by the fixation guidelines for the chosen connective sets and/or; c) adjust the connective sets by altering the system and increasing their combinatorial capacity.

When only compositional alternatives with the fully attended standards are produced, options for displacement and/or rotation are not available except for one standard ( $R$ ) for the $D$ connective set showed in Figure 9 . Adaptations in the connective sets will allow more patterns to be fixed, thereby expanding the combinatorial possibilities between threedimensional modules. The configuration extension beyond the epidermis of the building depends on the attributes of the connective sets and must promote fixations between modules.

Knowing the types of junctions present in each compositional pattern and the necessary connective attributes in each of them allows us to choose the patterns to be used in the generative model according to the fixing requirement. The degree of adjustment required by the connective set can be related to the shape characteristics that these modifications 
will entail, which allows us to generate compositional alternatives while knowing in advance the form and connective aspects of each pattern used.

The relationship also defined a generative process in which a set of solutions can be evaluated instead of producing only a single solution. Such a process allows for the generation of multiple alternatives from the combination of selected compositional patterns, either by the shape aspect and/or by the connective requirements. This will benefit the compositive process by anticipating the connective needs for each designed arrangement.

Therefore, in addition to allowing a catalog of choices the industry has pathways to change existing connective sets in varying degrees of adaptation, which may broaden the combinatorial possibilities of modules. It is not intended to generate a grammar defining an architectural language but to indicate a methodological path for grammar to be explored with this type of architecture. Based on the productive chain of each business, performance indicators (LunaVillareal, Pellicer, \& García-Rodríguez, 2017) can be included to promote production quality.

\section{Conclusions}

Knowing that personalization is an important requirement in architectural design and that this is hampered by the demands of industrialization, this work has studied the composition of blocks under the connection approach, extending customization beyond the epidermis of the building. Among the proposed objectives, this study demonstrated that the compositions depend on the connective attributes to be effective. In addition, a method has been developed that allows the combination of the various proposed compositional patterns by indicating the necessary connective characteristics.

Based on the knowledge of the fixation attributes, the degree of adjustment required by each connective set to meet the generated joins could be determined. Certain changes are simpler to meet and can complement the existing connective system, such as an increase in the number of holes and plates, definition of the location of the pieces and adjustment of their format, among others. Other changes, in turn, require further studies since the connections need to be remodeled to meet the connection.

In this sense, this study contributes to PMVA customization by promoting changes and enhancements to one of the parts that compose the module, the connective set, while maintaining the production of the chassis to incorporate other parts such as sealings, roofs, balconies, shading elements among others. A more elaborate connective set that anticipates constructive and geometric aspects to fix modules in different spatial relations allows for a greater compositive amplitude. At the same time, it preserves the other strategies of mass customization applied in the production of this type of architecture.

The extension of the shape variety with this type of architecture will facilitate the achievement of unique forms adapted to the implantation environment and the singularities required by the architectural projects, including the architect's design claims and the client's wishes. Modules with several types of prisms generate composite variety, such as trapezoidal prisms that allow for buildings with curvature. The possibility of misaligning the vertices of the modules and generating corner encounters with beams allows us to generate protrusions and recesses in the proposed compositive arrangement and to rotate one block in relation to the other.

Currently, PMVA is commonly used for applications that allow for the repetition of similar units, such as schools, lodgings, and hotels. However, the compositional variations made possible by expanding the connective set attributes will allow PMVA to be applied to other architectural programs more easily. Moreover, it helps the architect become better educated about modular construction in general to be able to explore architectural design with autonomy. The method provided allows design that has a certain degree of flexibility without sacrificing industrialized production. These changes in PMVA contribute to undoing stereotypes in industrialized architecture, which is considered synonymous with repetition, monotony and creative limitation.

\section{Acknowledgements}

The authors would like to thank the SIMMLAB (Laboratory for Simulation and Modeling in Architecture and Urbanism), specially Letícia Weijh for her help with the illustrations and the PROPAR (Post Graduate and Research Program in Architecture, Federal University of Rio Grande do Sul/Brazil). This paper springs from A Teribele's doctoral thesis "Arquitetura com Sistema Pré-Fabricado Modular Volumétrico: Modelo Generativo e Diretrizes de Fixação" (Architecture with Prefabricated Volumetric Modular System. Formal Generative Model and Connection Guidelines) and was supported by federal and regional grants from CAPES, CNPQ and FAPERGS. 
Alshayeb, M. J. (2011). Lean Production Using Modular Construction. Study of The ABC Company's Projects (Master of Science). The University of Kansas. Retrieved from https://kuscholarworks.ku.edu/handle/1808/8747?show=full

Anderson, M., \& Anderson, P. (2007). Prefab Prototypes: Site-Specific Design for Offsite Construction. New York: Princeton Architectural Press.

Azhar, S., Lukkad, M., \& Ahmad, I. (2012). Modular v. stick-built construction: Identification of critical decision-making factors. 48th Annual Conference of Associated Schools of Construction, 1(May), 1-8.

Bergdoll, B., \& Christensen, P. (2008). Home delivery : fabricating the modern dwelling. New York: Museum of Modern Art, New York.

Cameron, P. J., \& Carlo, N. G. Di. (2007). Piecing together modular: understanding the benefits and limitations of modular construction methods for multifamily development. (Master's thesis). Massachusetts Institute of Technology. Retrieved from https://dspace.mit.edu/handle/1721.1/42038\#files-area

Diez, R., Padrón, V. M., Abderrahim, M., \& Balaguer, C. (2007). AUTMOD3: The integration of design and planning tools for automatic modular construction. International Journal of Advanced Robotic Systems, 4(4), 457-468.

Diez, R., Pádron, V. M., Abderrahim, M., \& Balaguer, C. (2003). 3D Simulator of Modular Building Assembly by Automated Cranes. 20th International Symposium on Automation and Robotics in Construction ISARC 2003. The Future Site, 363-368. https://doi.org/https://doi.org/10.22260/ISARC2003/0059

Duarte, J. P. (2007). Personalizar a habitação em série: uma gramática discursiva para as casas da Malagueira do Siza. Lisboa: Fundacion Calouste Gulbenkian.

Fonyat, M. de A. R. (2013). A pré-fabricação e o projeto de arquitetura (Master's thesis). UFRGS. Retrieved from https://lume.ufrgs.br/handle/10183/80415

Furuse, J., \& Katano, M. (2006). Structuring of Sekisui Heim Automated Parts pickup system (HAPPS) to process individual floor plans. 23rd International Symposium on Automation and Robotics in Construction: ISARC 2006, 352-356. Retrieved from https://www.irbnet.de/daten/iconda/CIB12873.pdf

Gardiner, J. (n.d.). Exploring Prefabrication. New Architect Registration Board. Sydney. Retrieved from https://www.architects.nsw.gov.au/download/BHTS/Gardiner_James_exploring_prefabrication.pdf

Garrison, J., \& Tweedie, A. (2008). Kullman Offsite Construction. Modular Architecture Manual. Kullman Buildings Corporation. Lebanon: Kullman Buildings Corp.

Gassel, F. van, \& Roders, M. (2006). A Modular Construction System. How to design its Production Process? In F. Scheublin (Ed.), Proceedings the Joint CIB, Tensinet, IASS International Conference on Adaptability in Design and Construction, 3: 12.1-12.6).

Gonçalves, G. de G. (2015). Uma interpretação computacional do "De re aedificatoria" para igrejas históricas brasileiras (Doctoral dissertation). Unicamp. Retrieved from http://repositorio.unicamp.br/jspui/handle/REPOSIP/258034

Heather, D., Harding, C. E., Harding, R. H., MacDonald, R., \& Ogden, R. C. (2007). US 2007/0271857 A1. New York, NY: Patent Application Publication.

Huang, C.-H. J., \& Krawczyk, R. J. (2007). Web Based BIM for Modular House Development: Query Approach in Consumer Participatory Design. Em'body'ing Virtual Architecture: The Third International Conference of the Arab Society for Computer Aided Architectural Design. ASCAAD, 559570. Retrieved from https://cumincad.architexturez.net/doc/oai-cumincadworks-id-ascaad2007-044

Kieran, S., \& Timberlake, J. (2003). Refabricating architecture : how manufacturing methodologies are poised to transform building construction. New York: McGraw-Hill.

Knight, T. (2000). Shape Grammars in education and practice: history and prospects. Retrieved March 24, 2016, from http://www.mit.edu/ tknight/IJDC/

Knight, T. (2003). Computing with emergence. Environment and Planning B: Planning and Design, 30(1), 125-155. https://doi.org/10.1068/b12914

Knight, T. W. (1994). Transformations in design : a formal approach to stylistic change and innovation in the visual arts. Cambridge: Cambridge University Press.

Kolarevic, B. (2003). Architecture in the digital age : design and manufacturing. New York: Taylor \& Francis.

Koning, H., \& Eizenberg, J. (1981). The language of the prairie: Frank Lloyd Wright's prairie houses. Environment and Planning B: Planning and Design, 8(3), 295-323. https://doi.org/10.1068/b080295

Kovel, J. (2011). US 2011/0185646 A1. Portland, OR: Patent Application Publication.

Lawson, M., Ogden, R., \& Goodier, C. (2014). Design in Modular Construction. London; New York: CRC Press.

Lawson, R. M. (2007). Building design using modules. New Steel Constructio, 15(9), 1-16. Retrieved from http://www.newsteelconstruction.com/wp/building-design-using-modules-2/

Lawson, R. M., Ogden, R. G., Pedreschi, R., Grubb, P. J., \& Popo-Ola, S. O. (2005). Developments in pre-fabricated systems in light steel and modular construction. Structural Engineer, 83(6), 28-35.

Li, A. I. (2001). A shape grammar for teaching the architectural style of the Yingzao fashi (Doctoral dissertation). Text. Massachusetts Institute of Technology. Retrieved from https://dspace.mit.edu/handle/1721.1/8631 
Linner, T., \& Bock, T. (2012). Evolution of large-scale industrialisation and service innovation in Japanese prefabrication industry. Construction Innovation, 12(2), 156-178. https://doi.org/10.1108/14714171211215921

Luna-Villareal, K., Pellicer, E., \& García-Rodríguez, S. (2017). Performance indicators for developer and homebuilder Mexican companies: A Delphi study. Revista de la Construcción, 16(1), 133-144. https://doi.org/10.7764/RDLC.16.1.133

March, L., \& Steadman, P. (1974). The geometry of environment : an introduction to spatial organization in design (1st U.S. ed.). Cambridge: M.I.T. Press.

Mayer, R. (2012). A Gramática Da Habitação Mínima: Análise do Projeto da Habitação de Interesse Social em Porto Alegre e Região Metropolitana (Doctoral dissertation). Universidade Federal do Rio Grande do Sul (UFRGS). Retrieved from https://lume.ufrgs.br/handle/10183/67057

Modular Building Institute. (2011). Permanent Modular Construction. (No. 2011 Annual Report). Retrieved from http://www.modular.org/documents/document_publication/2011permanent.pdf

Moghadam, M., Alwisy, A., \& Al-Hussein, M. (2012). Integrated BIM/Lean Base production Line Schedule Model for Modular Construction Manufacturing. Construction Research Congress, 1271-1280. https://doi.org/https://doi.org/10.1061/9780784412329.128

Mullens, M. A. (2011). Factory design for modular homebuilding : equipping the modular factory for success. Winter Park: Constructability Press.

Mullens, M. A., \& Kelley, M. E. (2004). Lean Homebuilding Using Modular Technology. Housing and Society, 31(1), 41-54. https://doi.org/10.1080/08882746.2004.11430497

$\mathrm{Na}$, L. (2007). Investigation of the Desginers' and General Contrators' Perceptions of Offsite Construction Techniques in the United States Construction Industry (Doctoral dissertation). Clemson University. Retrieved from https://tigerprints.clemson.edu/all_dissertations/81

Nahmens, I., \& Ikuma, L. H. (2012). Effects of Lean Construction on Sustainability of Modular Homebuilding. Journal of Architectural Engineering, 18(2), 155-163. https://doi.org/10.1061/(ASCE)AE.1943-5568.0000054

Nasereddin, M., Mullens, M. A., \& Cope, D. (2007). Automated simulator development: A strategy for modeling modular housing production. Automation in Construction, 16(2), 212-223. https://doi.org/10.1016/j.autcon.2006.04.003

Piazzalunga, U., \& Fitzhorn, P. (1998). Note on a three-dimensional shape grammar interpreter. Environment and Planning B: Planning and Design, 25(1), 11-30. https://doi.org/10.1068/b250011

Piroozfar, P. A. E., \& Piller, F. T. (2013). Mass Customisation and Personalisation in Architecture and Construction: an introduction. In P. A. E. Piroozfar \& F. T. Piller (Eds.), Mass Customisation and Personalisation in Architecture and Construction (p. 272). Routledge.

Pottmann, H., Asperl, A., Hofer, M., Kilian, A., \& Bentley, D. (2007). Architectural geometry. Exton: Bentley Institute Press.

Prats, M. (2007). Shape Exploration in Product Design: Assisting Transformation in Pictorial Representations (Doctoral dissertation). The Open University. Retrieved from http://oro.open.ac.uk/54366/

Rocha, C. G. (2011). A conceptual framework for defining customisation strategies in the house- building sector (Doctoral dissertation). Universidade Federal do Rio Grande do Sul (UFRGS). Retrieved from https://lume.ufrgs.br/handle/10183/38795

Santos, L. F. B. S. Dos. (2009). Sistemas Generativos de Projecto : Integração de Ferramentas Digitais no Projecto de Arquitectura Aplicação ao Caso de Estudo: a Casa Pátio da Medina de Marrakech. (Master's thesis). Universidade Técnica de Lisboa. Retrieved from https://fenix.tecnico.ulisboa.pt/downloadFile/395139490927/Dissertacao_Luis_48942.pdf

Sass, L. (2005). Wood Frame Grammar: CAD Scripting a Wood Frame House. Computer Aided Architectural Design Futures 2005 , 383-392. https://doi.org/10.1007/1-4020-3698-1_36

Schoenborn, J. M. (2012). A Case Study Approach to Identifying the Constraints and Barriers to Design Innovation for Modular Construction (Master's thesis). Faculty of the Virginia Polytechnic Institute and State University. Retrieved from https://vtechworks.lib.vt.edu/handle/10919/32397

Smith, R. E. (2011). Prefab Architecture: A Guide to Modular Design and Construction. Hoboken: John Wiley \& Sons.

Staib, G., Dörrhöfer, A., \& Rosenthal, M. (2008). Components and systems : modular construction : design, structure, new technologies. Basel; Boston; Berlin: Birkhauser.

Stiny, G. (1980). Kindergarten grammars: designing with Froebel's building gifts. Environment and Planning B: Planning and Design, 7, $409-462$. https://doi.org/10.1068/b070409

Stiny, G. (1981). A note on the description of designs. Environment and Planning B: Planning and Design, 8(3), $257-267$. https://doi.org/10.1068/b080257

TREMBLAY, J.-R. (2010). WO 2010/142032 A1. Quebec, QC: International Application Published Under The Patent Cooperation Treaty (PCT).

Velamati, S. (2012). Feasibility, Benefits and Challenges of Modular Construction in High Rise Development in the United States: a Developer'S Perspective (Master's thesis). Massachusetts Institute of Technology. Retrieved from https://dspace.mit.edu/handle/1721.1/77129

Vibaek, K. S. (2011). System Structures In Architecture. Constituent elements of a contemporary industrialised architecture. (Doctoral thesis). The Royal Danish Academy of Fine Arts. Retrieved from https://kadk.dk/sites/default/files/downloads/case/systemstructures.pdf

Wang, Y. (1998). 3D architecture form synthesizer (Master's thesis). Massachusetts Institute of Technology. Retrieved from https://dspace.mit.edu/handle/1721.1/51561\#files-area

Wang, Y., \& Duarte, J. P. (2002). Automatic generation and fabrication of designs. Automation in Construction, 11(3), $291-302$. https://doi.org/10.1016/S0926-5805(00)00112-6. 